\title{
Fractographic Analysis of Co-P-SiC Electrocomposite Coatings by Stereoscopic Reconstruction
}

\author{
Sriram Vijayan ${ }^{1}$, Amit Datta ${ }^{2}$, John. D. Carpenter ${ }^{2}$, Mark Aindow ${ }^{1}$ \\ ${ }^{1}$ Department of Materials Science \& Engineering, Institute of Materials Science, University of \\ Connecticut, 97 North Eagleville Road, Storrs, CT 06269-3136 \\ ${ }^{2}$ US Chrome Corporation, 175 Garfield Avenue, Stratford, CT 06615
}

Electrolytic Hard Chrome (EHC) coatings are widely employed to improve the surface performance of engineering components. The superior wear and corrosion resistance, combined with the processing advantage of being able to coat surfaces with complex geometries, makes EHC a preferred choice for coating critical components like aircraft landing gear, hydraulic actuator cylinders, etc. There are, however, some significant environmental problems with EHC coatings due to the release of hexavalent chromium aerosols during the electrodeposition process. Moreover, there is a significant fatigue debit for EHC-coated components due to the inherent micro-cracks present in the coatings; this is a major cause for concern in critical low cycle fatigue applications.

Over the past decade there has been a shift in the industry towards environmentally safer and technically superior alternatives. Nanostructured cobalt - phosphorous - silicon carbide electro-composite coatings have been identified as an environmentally safe candidate material that has the potential to deliver the desired results. In previous work by Carpenter et al. [1] it has been shown that there is actually a fatigue credit associated with Co-P-SiC coatings for samples evaluated in rotating beam fatigue tests [1]. More recently, we have shown that there is a fatigue debit for similar samples evaluated in uniaxial tensile fatigue, but the origins of the difference in this behavior have not yet been established. The objective of the present study was to investigate the crack initiation mechanisms in Co-P-SiC coated tensile samples of AISI 4340.

Initial SEM observations (e.g. Fig. 1) suggested three possible mechanisms for crack initiation: 1) cracks forming due to de-bonding at the matrix-particle interface; 2) fracturing of $\mathrm{SiC}$ particles due to cyclic loading; and 3) both of these processes occurring simultaneously. Stereoscopic SEM imaging was used to better reveal the topographic details of the fracture surfaces. Figure 2 is an example of a 3D reconstruction produced using the MEX software package from a stereo pair of SEM images. The topographic features in such reconstructions were related to the distribution of the $\mathrm{SiC}$ reinforcements by acquiring elemental X-ray maps from the same regions. An example of these data is shown in Figure 3 , wherein the $\mathrm{Si}$ map reveals the location of the $\mathrm{SiC}$ within the Co-P matrix. The main conclusion of these observations is that crack initiation in these electrocomposite coatings occurs primarily at the Co-P matrix / SiC particle interfaces within the coating. These cracks then propagate towards the coating/substrate interface and into the substrate.

\section{References}

[1] J. Carpenter, A. Kertesz, A. Datta, Adv Mater Proc 167 (2009) 25. 

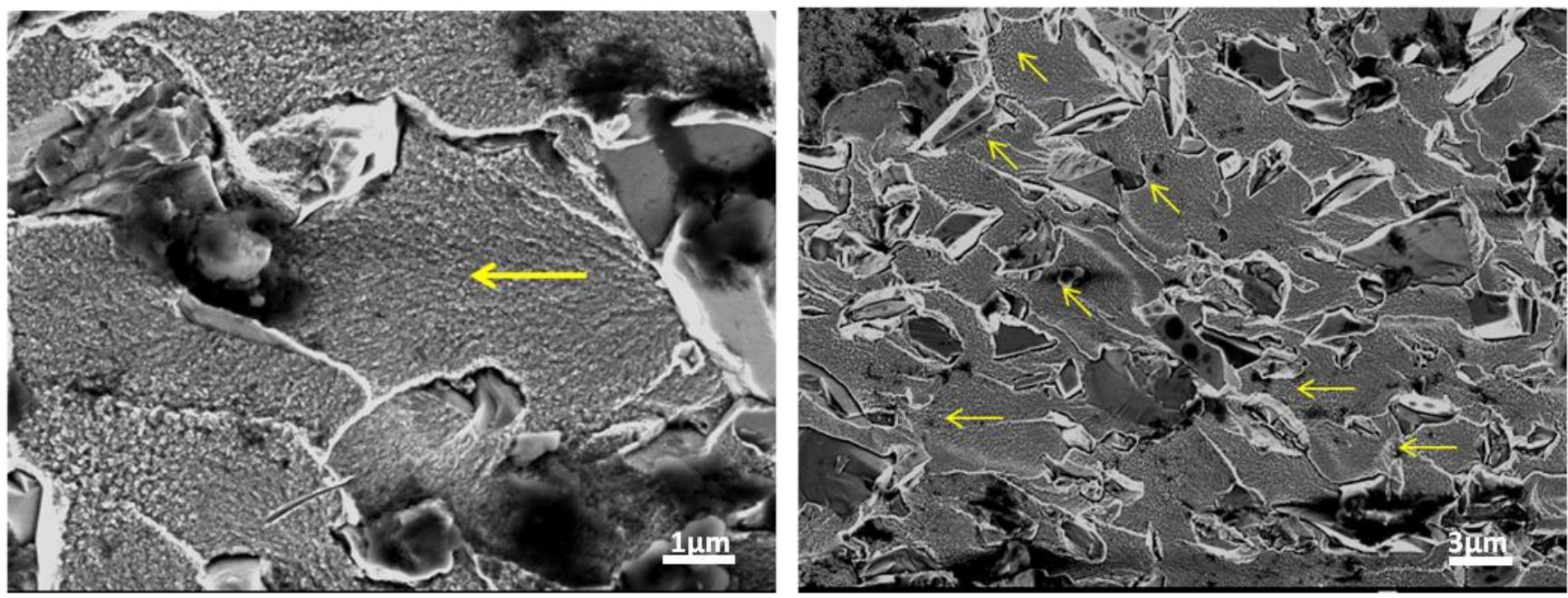

Figure 1: Secondary electron SEM images showing: (left) crack initiation; (right) crack propagation.

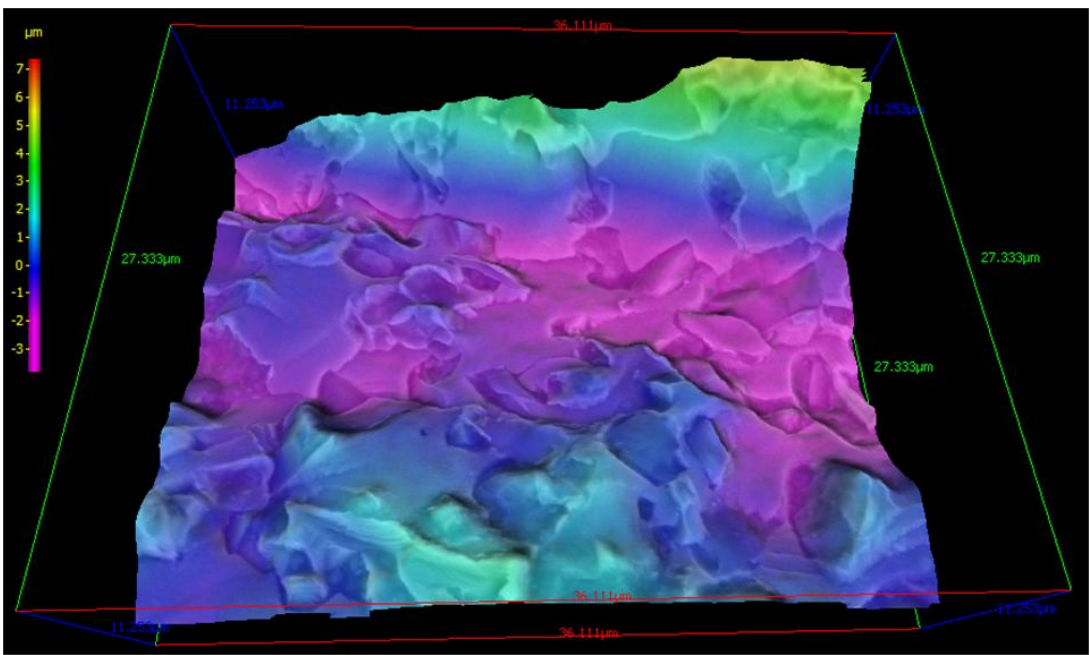

Figure 2: 3D reconstruction of a fracture surface produced using the MEX software
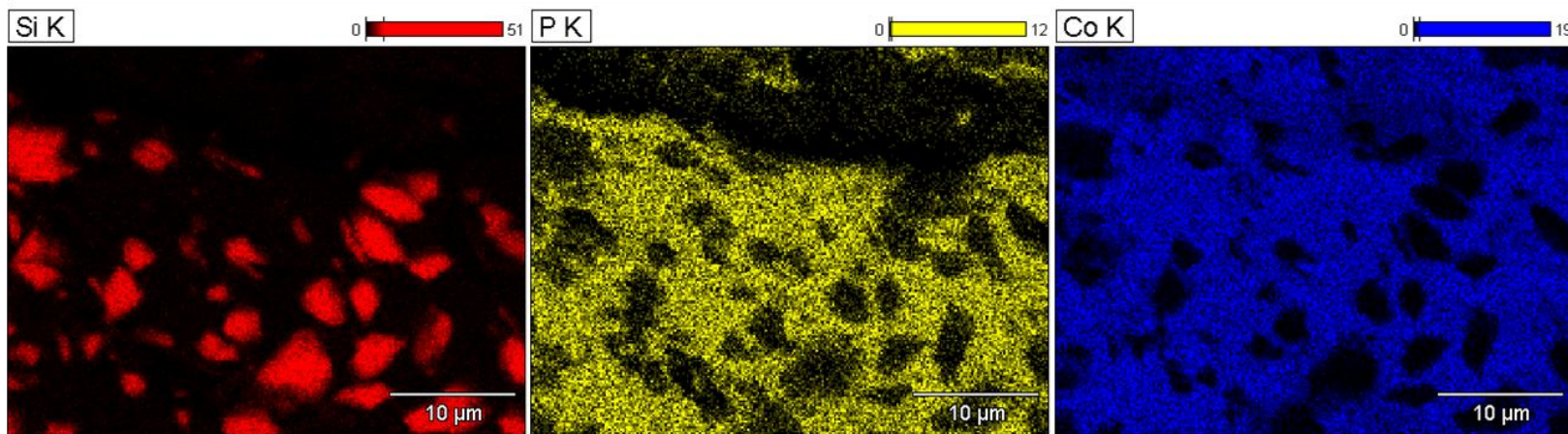

Figure 3: Elemental maps obtained from a fracture surface revealing the location of the SiC particles. 